\title{
Malignant Intracranial Neoplasm
}

National Cancer Institute

\section{Source}

National Cancer Institute. Malignant Intracranial Neoplasm. NCI Thesaurus. Code C5114.

A malignant neoplasm involving the intracranial space. 